\title{
METHODOLOGICAL INSIGHTS FROM RESEARCHING TEMPORALITY IN FAMILIES WITH TEENAGE CHILDREN
}

\author{
Sophie Sarre and Jo Moran-Ellis
}

\begin{abstract}
The often unremarked processes through which gender and generation play out in families with teenage children in, through, and over time, was the topic of a mixed qualitative methods study, drawing on the accounts of multiple family members - 14 and 15 year olds and their resident parent(s). Using this as a case study the paper critically considers a number of methodological, ethical, and political issues faced in undertaking the research, particularly with respect to research with children. These pertain to challenges of a social constructionist approach and to research from multiple perspectives. We argue that there are paradoxes and contradictions that arise between a social constructionist approach and the practicalities of carrying out research into dynamic phenomena, such as "generationing”, particularly when trying to understand this from multiple perspectives. But rather than consider these as flaws we show how they are in fact opportunities for insight into the interplay between the structural and the dynamic nature of intergenerational relations.
\end{abstract}

Keywords: family life, sociology of childhood, social construction, multiple perspectives, mixed methods, temporality, teenagers

Acknowledgements: The study used to illustrate the arguments in this paper was funded by a studentship from the Economic and Social Research Council (grant number ES/I900888/1). We would like to thank Geoff Cooper for his valuable supervisory contribution, the participants in the research for their commitment, and the editorial team of this special issue for their work and their helpful suggestions.

Sophie Sarre, Ph.D. (the corresponding author) is a Research Associate at King's College London, National Nursing Research Unit, Faculty of Nursing \& Midwifery, 57 Waterloo Road, London, United Kingdom, SE1 8WA. E-mail: sophie.sarre@kcl.ac.uk

Jo Moran-Ellis, Ph.D. is Professor of Sociology at the University of Sussex, Brighton, United Kingdom, BN1 9RH. E-mail: j.moran-ellis@sussex.ac.uk 
Since the 1990s there has been a growing momentum to the sociological move to: engage with childhood as a simultaneously socially constructed phenomenon and a structural division; position children as social actors; explore the ways in which their capacity to be agentic is played out or resisted; and work with the implications of that for theorising the nature of the social and society (see Alanen \& Mayall, 2001; Hutchby \& Moran-Ellis, 1998; James, Jenks, \& Prout 1998; James \& Prout, 1990; Qvortrup, 1994).

This interest in childhood and children's lives has necessarily been accompanied by developments in methods and methodology (Alderson, 1995; Christensen \& James, 2000; Davis, 1998; Harden, Scott, Backett-Milburn, \& Jackson, 2000; Kellett, Forrest, Dent, \& Ward, 2004) including multiple perspectives studies involving children (Brannen, 1996; Gabb, 2008; Gillies, Holland, \& Ribbens McCarthy, 2003; Gillies, Ribbens McCarthy, \& Holland, 2001; Harden, MacLean, Backett-Milburn, \& Cunningham-Burley, 2012; Zeiher, 2001).

However, as this special issue suggests, over this time there has perhaps been more emphasis on the utilisation of these methodological approaches than there has been on critically reflecting on the contradictions and paradoxes which are inevitable given the embedded assumptions within social constructionism as a perspective, multiple methods as a methodology, and research with children as the empirical expression of a theoretical endeavour to locate children in society in a more sociologically informed way than previously.

In this paper we take up two particular challenges which we believe need to be addressed: firstly, the resolution of tensions between a social constructionist approach to dynamic phenomena and the realities of research design and practice that rely on pre-existing categories; and secondly, the challenge in multiple perspectives research of positing the accounts of participants alongside each other such that children's voices are as recognised and valued as adults' voices, both individually and as members of family households. We explore these two challenges using the example of a qualitative mixed methods study looking at temporality in the lives of teenage children and their parents. After sketching out the background, aims, and methods of the study, we examine these challenges at different points of the research process: recruitment, generation of data, the pragmatics of research, and means of analyses. We conclude that the paradoxes and contradictions that arise in carrying out research on the social construction of generation, and doing so from multiple perspectives afford us greater insight into the interplay between the structural and the dynamic nature of intergenerational relations. 


\section{The Study}

The study explored temporality in families with a 14- or 15-year-old child, living within or across households (Sarre, 2011) ${ }^{1}$. It was premised on a conception of "timescapes" (Adam, 1998, 2000, 2004), or temporal landscapes, in which time is multi-dimensional, shifting, and subject to manipulation. For instance, time is not solely a measure of duration, pace, and rhythm. It can also be used for political ends - to control, to punish, and to discipline. Other dimensions, or qualities, of time arise from our subjective experience of it (whether we feel harried, or whether time seems to drag). Time is also imbued with meanings - timeliness, giving appropriate time to show we care, special times, and so on. The term "temporality" is used here to describe the coming together of the temporal and the social, whereby different dimensions of time not only provide a context that may shape or colour our experience, but a resource we draw upon and manipulate to "go on" in social living.

Existing research shows that gender and generation are reflected and produced in the ways that mothers and fathers, adults and children: use their time (Office for National Statistics [ONS], 2008); experience their time (Craig, 2007; Davies, 1990; Jurczyk, 1998; Southerton \& Tomlinson, 2005; Sullivan, 1997); and in the legitimacy afforded to their uses of time (Daly, 1996; Gershuny, 2004; Sarre, 2013). Family life is one, arguably distinct, arena in which time, gender, and generational relations intersect. It has also been argued that creating familiality requires a certain kind of temporality (Everingham, 2002; Galinsky, 1999; Southerton, 2003), or the operation of certain "temporal principles", such that "family practices” (Morgan, 1996) also have an important temporal dimension (Morgan, 2011).

Specifically, then, the study set out to answer three related questions:

1. What are the dimensions of temporality in families with teenagers (including but not restricted to the temporality of family practices)?

2. How do mothers', fathers', sons' or daughters' timescapes differ, and in what ways are they similar?

3. How might temporality operate (or be made to operate) in families to position family members as more or less gendered and/or generational beings (or to resist, modify, or obscure these positions)?

Children, mothers, and fathers were placed alongside each other in terms of the research focus, the data collection, and the analysis. With respect to research focus we were interested in the contribution of children to the (re)construction of generational and gender ordering through temporal processes. In terms of methods the study aimed to explore the research questions from the perspectives of teenage children and their resident parent(s), and used data collection tools designed to engage all parties. In the analysis it was seen as important to treat each person's account of their experience as having equal worth, and to try to "hear" mothers, fathers, and children's voices at equal "volume”.

\footnotetext{
${ }^{1}$ This was a doctoral study carried out by Sophie Sarre under the supervision of Jo Moran-Ellis and Geoff Cooper at the University of Surrey (Sarre, 2011). The design of the research and research tools, and all recruitment and data collection, was carried out by Sophie Sarre (referred to here as SS).
} 


\section{Data collection}

The study used a number of qualitative methods to generate data. First 14- and 15year-old children and their resident parent(s) were asked to participate in a joint task-based interview (the Household Portrait) followed by individual semi-structured interviews at home. All participants were also invited to complete either or both of two additional tasks - a personalized inventory of time-related objects (PITO) and a reflective time diary. Because of the extra burden they represented, diaries and PITOs were presented as optional extras, flagged in recruitment material but not a necessary condition of participation.

The Household Portrait - rendering timescapes, temporalities and their negotiation visible. Doucet designed the "Household Portrait" (HHP) to explore gendered divisions of labour (Doucet, 1996, 2000, 2001, 2006). It is essentially a joint, task-based interview which provides opportunities for the creation of visual data, discussion, and reflection. Both alone and in combination each of these aspects offers a number of benefits. First, both the process and the output provide valuable data. Also, visual materials created by participants can act as mediators between researcher and participant (Christensen \& James, 2000). They make something "manifest" both to the researcher and the participant, and can be discussed as a "joint referent". Lastly, by allowing respondents to see and reflect on the data that they produce, they are enabled in carrying out a degree of primary analysis on their data (Doucet, 1996).

This study used an adapted form of HHP which included children as social agents. An excised, pseudonymised version of a completed HHP is represented in Figure 1. (A slightly adapted form was used in lone-parent families).

Participants were asked to decide together, through discussion, who (alone or in combination with another) tended to perform each of several time-related tasks or have responsibility for time-related decisions in the household. The items were chosen as common temporal themes in family life around: synchronising time with the family (red); regulating the child's time (blue); anticipating (green); reacting (orange); and keeping tabs (yellow). Participants were invited to add any time-related activities or responsibilities which they felt were significant in their family life. Once all the rows had been completed participants were asked: whether they felt this categorization captured time in their household; whether the HHP they had created reflected the allocation of these types of tasks more generally within their family, beyond the specific tasks asked about; and whether they were surprised at the picture that emerged. They were also encouraged to talk about reasons behind the pattern of time in their family. These reflections generated further data. 
International Journal of Child, Youth, and Family Studies (2014): 5(4.1) 666-685

Figure 1. Extract from a completed Household Portrait interview table.

\begin{tabular}{|c|c|c|c|c|c|c|c|c|c|c|c|c|c|}
\hline $\begin{array}{l}\text { Who does the } \\
\text { following? }\end{array}$ & * & and & as & $30^{\circ}$ & as & and & (3) & sol & Nons & and & 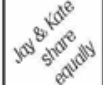 & 1. & $\mid \begin{array}{ll}3 \\
n_{0}\end{array}$ \\
\hline $\begin{array}{l}\text { Deciding what time to } \\
\text { eat (days off) }\end{array}$ & & & & & & & & & & & & & 8 \\
\hline $\begin{array}{l}\text { Deciding to have a } \\
\text { housenold family outing }\end{array}$ & & & & & & & & & & & & & \\
\hline $\begin{array}{l}\text { Making sure Ichild } \\
\text { leaves for school on } \\
\text { time }\end{array}$ & & & & & & & & & ) & & & & \\
\hline 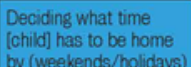 & & 0 & & & & & & & & & & & \\
\hline $\begin{array}{l}\text { hecking the } \\
\text { whereabouts of [child] } \\
\text { when not with parent }\end{array}$ & & & & & & & 0 & & & & & & \\
\hline Arranging Chidcoare & 0 & & & & & & & & & & & & \\
\hline $\begin{array}{l}\text { Taking time of for sick } \\
\text { household member }\end{array}$ & & 0 & & & & & & & & & & & \\
\hline $\begin{array}{l}\text { Remembering School } \\
\text { Events }\end{array}$ & & & P & & & & & & & & & & \\
\hline $\begin{array}{l}\text { Knowing where family } \\
\text { members are at ary } \\
\text { one time }\end{array}$ & & 0 & & & & & & & & & & & \\
\hline Drving Jay to Swimming & & & & & $X$ & & & & & & & & \\
\hline
\end{tabular}


Interviews - eliciting timescapes, temporalities, and articulations. Individual interviews were based around: the temporal impacts of paid work and school work in the household; the temporal effects of having or being a child and how these may have changed over time; values on time-use; making time together and taking time apart. Following Solberg (1996), the children's interview schedule was as "generation-neutral" as possible in order to get behind age-related assumptions, and better explore when age or generation "mattered".

\section{Personalized inventory of time-related objects - keeping track of time and time} management. A third research tool was designed to capture something of the way that an awareness of time permeates our lives; and also to supplement the HHP in getting at how time is measured, regulated, and monitored in families, and who were the performers and subjects of such practices. The PITO was essentially a spreadsheet in which participants were asked to note all the things they used to keep track of time, how often they used them, and the reasons for using them.

Reflective time diaries - temporality as lived experience. Finally participants were invited to create a reflective time diary over a period of up to one week. According to preference, people could choose to do this by means of an audio diary, a written diary, or by e-mailing diary entries to the researcher. The remit given to diarists was wide, but respondents were steered towards their experiences of time - for instance, whether they felt rushed, nostalgic, bored; whether there was anything to do with time that had made them frustrated, annoyed, glad; whether they had been reminded of or looked back on things in the past or had spent time thinking about the future.

\section{Analysis}

The multiple datasets created by each person were used to build a more rounded picture of the participant, while remaining sensitive to the different research contexts. Data were also collated and analysed by family to create a picture of each family's timescape and its negotiation from multiple perspectives. Finally, data were also analysed across families, from different standpoint perspectives. Some of the benefits and challenges of multiple perspectives analysis are discussed further below.

\section{Recruitment}

Recruitment aimed at children was attempted through youth organizations (with SS attending regular scheduled activities and approaching individuals on an ad hoc basis) and through schools (via published material). Given the failure of this recruitment approach (discussed further below) parents were then targeted through community events, online fora, e-lists, newsletters, snowballing, and word-of-mouth.

\section{The sample}

Parents and teenage children living in 14 households in London and the South East of England took part in the study. Nine were two-parent household families and five were loneparent household families. Fieldwork was carried out between February and October 2010.

\section{Statement on ethical issues}

The study was given favourable opinion by the University of Surrey Research Ethics Committee. Ethical engagement is emergent and situated. A number of ethical considerations came to light during the processes of ethics committee approval, research design, recruitment, 
data collection, analysis, and choosing terminology in writing this paper. Reflecting this, rather than imposing a false bracketing off of ethical issues, we consider them as they arise in the narrative of this paper.

\section{Researching Social Construction in Family Life}

The study took a social constructionist perspective on the constitution of family, gender, and generation, which is now somewhat the convention in childhood studies. Drawing on this empirical study we discuss here three related "problems" that routinely arise out of this particular stance, and which have received less attention than they should in the field. Firstly, social construction emphasises “doing”, context, salience, and emergence in creating and reshaping social positions. But labels and categories used to select cases in which to study those processes rely on and perpetuate, to some degree, a priori constructions (in this case "teenager", "mother”, "father”). Secondly, and similarly, researching from standpoints also assumes meaningful pre-existing differences, even though the making of these is the object of study. Lastly, we address the problem of producing the very phenomenon under consideration through the mechanisms of the research process. This last point arises out of what Giddens (1993) argues is the double hermeneutic with which social science in particular has to grapple. In effect, he notes, in describing social phenomena in the world, the social scientific concepts used contribute to the existence and shape of that phenomenon. Giddens explains this as an interdependence between the ideas with which social science works, and the subject matter with which it is engaged:

Sociology ... stands in a subject-subject relation to its "field of study", not a subjectobject relation; it deals with a pre-interpreted world in which the meaning developed by active subjects actually enter into the constitution or production of that world; the construction of social theory thus involves a double hermeneutic... (p. 154)

Hence in researching time in families from the perspective of mothers, fathers, and teenage children, these categories are all partially constituted in and through various elements of both the methodology of the research and the conceptual apparatus with which it works. Despite this being a well-established issue in social scientific thinking, it generally receives little attention in writings about research with children. So, in this section we explore how on the one hand these three tensions have to be tackled as a question of pragmatics and practice, while at the same time they afford analytic insight into the phenomenon in action.

\section{Categories}

The tension between capturing emergent processes (such as the ongoing construction of generation and gender) using prior categories (teenage child, mother, father) is eased through the use of criteria that are mutually recognised by the researchers, participants, and gatekeepers. Following Henwood, Griffin, and Phoenix's (1998, p. 7) definition of standpoint, recruitment to this study was based on the assumption that mothers, fathers, and 14- to 15-year-old children have, to some degree, concrete, materially grounded, or shared experiences and/or socially defined group identities, even if not collectively articulated political viewpoints.

With respect to children, despite an emphasis on generation and generational categories as emergent, this study was not unusual in sampling based on age category both for theoretical and pragmatic reasons. The choice of the particular age bracket was based on previous evidence (Lewis, Noden, \& Sarre, 2008; Lewis, Sarre, \& Burton, 2007; Sarre, 2010) that 14 or 15 year olds had a distinctive relationship to time. Furthermore, given that schools 
were to be used as a recruitment pathway, a narrower band of specific year groups made it easier for schools to administer. This sampling strategy reflects a societal condition under which generational categories are structurally fixed in particular contexts, for example in schooling in the United Kingdom. This structural demarcation also extends to processes of research with children, whereby ethics committees treat people under the age of 16 as a special category requiring, for instance, police checks to be carried out on the researcher. So, whilst we can argue that generational categories emerge through interaction, this also acknowledges that structural conditions (re)produce generational orderings. Furthermore, there is a degree of shared experience that arises through the operation of this structural ordering. Children live in a context of age-specific policies and are organised into age cohorts in schools, sports, and leisure activities. Age is thus a meaningful part of children's lives (James et al., 1998) and is contingently emergent and/or fixed. This study revealed the processes by which age (and birth order) operated as a meaningful category both in its contingent and fixed forms, as well as highlighting the ways in which this played out in the temporal landscapes of multiple family members, as the extracts below illustrate:

I'm a kid and I don't have to - I'm a teenager, sorry, sorry - I'm a teenager so I don't have to go to work. (Son interview)

I suppose the whole point of adolescence is getting to a point where you take responsibility for these things yourself. (Mother interview)

I think most older children get the slightly rough end of the stick because they're teaching their parents how to be parents. (Father interview)

They hit, sort of, 12, you know there's that funny feeling when you go out for the first time and you leave them alone [...] Every couple of years you let go of another thing. (Mother interview)

In the face of this pull toward categorization, the conceptual and methodological approach taken in the study aimed to minimise the "objectification" of mothers, fathers, and children by: taking a relational approach based on the assumption of agency as well as constraint for all family members; looking at family relations from the perspective of several family members; treating each account as of equal worth; and inviting participants to influence the research agenda through the reflective creation of artefacts.

The tension between category and emergence persists even in writing about the study. Conventionally the practice would be to use the term "young people" for those participants who are 14 and 15 years old. However, throughout this paper we use the word "child" when referring to these participants. This does not belie assumptions about the nature of children's pre-adult identity. Rather it is because the focus of the study was children's place in family ordering, generational relations, and the ongoing situated processes of positioning on a generational continuum of what is regarded as "child-like" - "adult-like”. We also use the term "teenager". Although we may balk at imposing the term to characterise respondents of a certain age, especially in the light of the negative connotations frequently associated with the label, it had clear cultural significance. The 14 and 15 year olds and parents frequently used the term to refer to themselves and their children, as well as to "generalised other" teenagers; and the "teenage years" were regarded as a somewhat distinct period of childhood, not least with respect to time-use and time sovereignty. 


\section{The double hermeneutic}

Here we argue that by taking a reflexive approach to researcher/participant interactions in the research process, analytic use can be made of the moments where the play of the double hermeneutic becomes visible in the dialogic data. For example, where the research process elicits a reaction from the participants, the dynamic of this can serve as another level of data to be analysed. We present here two examples from HHP interviews to illustrate our point. In one lone-parent household the HHP exposed considerable historic and ongoing tension, and elicited overt conflict. The researcher had asked whether and how the mother and son knew about each other's whereabouts when not together:

I: $\quad$ Either one of you may be

MUM: He doesn't care where I am.

I: $\quad$ in or out as it were.

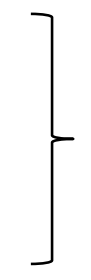

[Talking at the same time]

SON: You don't always know where I am. I'll sometimes say "Oh I'm in town" but where that could be-

MOTHER: No, but I do want to know. You're supposed to call me when you're going to be somewhere where I wouldn't expect you to be.

SON: I'm in Year 11 now though. If I just say "I'm in [the neighbourhood]", that's fine, right? I don't need to tell you exactly where in [the neighbourhood] I am.

MOTHER: [To son] Are we arguing about this or are we trying to come up with an answer?

I: $\quad$ Well it's very interesting to have the argument actually! [mother and interviewer laugh nervously]

MOTHER: Well, if I did know where he was all the time it would be entirely down to my effort.

I: $\quad$ Right, OK, that's interesting.

SON: Maybe-

MOTHER: He occasionally remembers to call me to say "I'm going out", but more often than not -

SON: On days where it's given that I'm going out, like on Fridays when I go out before football, I don't really want to tell you because I'm just going out anyway. You know that.

We can make two observations about this extract. Firstly, the study found that sharing time, putting in time, and making time available built a sense of togetherness. The encounter illustrated in the above extract demonstrates inverse processes at work (both in terms of the interview interaction and in terms of the "story"). These processes pertain to keeping oneself apart, refusing to account for your time to another, and asserting your autonomy, which are 
all perhaps necessary to establish a sense of individuality (rather that togetherness). This endeavour is perhaps particularly pertinent in terms of generation, where children are trying to assert their autonomy and independence from within social, moral, and legal frameworks of dependence. Secondly, it is included as a reminder that joint interviews may not only reveal but elicit family interactions that can be difficult to manage (Harden et al., 2012). The presence of the interviewer may foster this conflict through being regarded by one or both parties as a kind of mediator or witness. At the same time, the participants are both performing the kinds of negotiating that produces their generationally ordered relationship to time spent together/apart/at home/elsewhere, and recognising that this as not a unified answer but a process of arguing. Herein lies the double hermeneutic: In seeking an account of time, the participants reproduce the dynamics of conflict over time (and location) and the researcher becomes enrolled in nominating this as data in itself, but out of a move that both "saves" the situation diplomatically and adheres to the initial reassurance that there are no right answers. Thus, we see the complexity of the hermeneutics of the participants' interaction and the researcher's.

In our second example disagreement was aired in a light-hearted way. Knowing that the researcher had a son of a similar age to the boy being interviewed ${ }^{2}$ (and perhaps assuming that her views and experiences would align with their own), mother and son each goodhumouredly attempted to use the researcher to support their own positions. But the scenario is more than an ethically uncomfortable encounter. The process of the research elicits one of the themes of enquiry (in this instance the dynamics of contested constructions of an "appropriate bedtime for a 14 year old”), and once laid bare this provides valuable data:

SON: [Reading from the chart] "Deciding what time [child] goes to bed". Well I have absolutely no input on that!

DAD: Me neither.

SON: That's going straight into mum's one! For the tape, I go to bed far too early for a 14 year old. You should put this on the news!

I: What time do you go to bed then?

SON: Too early

DAD: Don't ask me

MUM: What time does your son go to bed?

I: $\quad$ Oh no I'm not going to get embroiled in these ...

SON: No just tell. Just say.

I: $\quad$ Not as early as I think he should.

SON: Is it 9:00 or over?

I: $\quad$ No, I can't possibly start wading into family disputes.

\footnotetext{
2 Depending on the recruitment pathway, for a number of reasons SS decided to reveal to potential participants that she was a mother of teenage children. In other instances participants tended to ask about this on the telephone or at the first meeting. The subject of the research, and the fact that interviews were carried out in people's homes, contributed to such conversations.
} 
SON: It's probably ... What time is it? Just tell us. Please. Please.

MUM: Tell us, we won't mind

I: $\quad$ [Hesitatingly] He goes to bed at 9.30

MUM: [To the sound of Handel’s Messiah] Hallelujah!! Hallelujah!! See. See. See

SON: He's younger than me. What year's he in? 8 or 9?

I: $\quad 9$.

MUM: [Triumphant] Yes!!

SON: It's still too early though

DAD: Unlucky son.

This exchange illustrates Giddens' (1993) claim that: “Lay actors are concept-bearing beings, whose concepts enter constitutively into what they do; the concepts of social science cannot be kept insulated from their potential appropriation and incorporation within everyday action" (p. 13). The participants are working with the notion of "bedtime" and the management of that (one feature of the research), and at the same time are engaged in an exchange in which the relevant norms to be applied to the concept, and the meaning of the concept of bedtime, are contested between the three participants, with (eventually successful) attempts to enrol the researcher as a further "lay actor" who can lend weight to one side of the argument or the other. The idea of bedtime being meaningful in respect of normativity and age/generation/household structure is both a social scientific one and a lay one, and there is exchange and appropriation between these domains.

\section{Hearing the Child in Researching Family Life}

We now focus on what we see as a second tough question: how to integrate the child's perspective into both the method and in the analysis. As we show below, this challenge also presents itself across the research process, at the stage of recruitment, in relation to the practicalities of conducting the research, and in relation to analysis of the multiple datasets generated by the research design described above.

\section{Difficulties and limitations in recruitment}

When children are invited to take part in research they are commonly accessed through parents or through schools. Family life and school life are also common themes in research involving children. This study does not break with either of those conventions. We make no apology for the subject matter of the research, particularly since teenagers (especially those teenagers unencumbered by the labels troubled or troublesome teenagers) are under-represented in family research. But it is worth considering some of the difficulties faced in recruiting children to the study.

As a deliberate political stance, signalling an interest in children's voices and children's significance as social actors and agents, initial recruitment strategies were directed towards the 14- and 15-year-old targets. Concerted efforts were made to recruit children through settings beyond home and school. Twelve youth and community groups were contacted (youth centres, sports clubs, music organizations, adventure playgrounds, a local authority youth council, and a community expo). In all but one case permission was given for 
the researcher to spend time at these sites, speaking to children about the research and inviting them to participate using an information sheet aimed at the children (though this made clear that parental consent would be required). Nobody took up the invitation. In a parallel recruitment strategy three secondary schools were also approached, and one agreed to distribute 180 information sheets addressed to children. Nobody took up the invitation. Several months later this exercise was repeated with another year group. Nobody took up the invitation. In the end, although over 400 information leaflets had been distributed to target children, and many hours had been spent attempting face-to-face recruitment with this group, all families who participated were accessed through appeals to parents (some of whom were themselves accessed through school-based communication channels) ${ }^{3}$.

Given her initial drive to target children in order to emphasise children's agency, SS has to admit that the majority of children appeared to vote with their feet and decline to participate. Unwilling to abandon what she felt was a key element in the research design (including the voices of children) she therefore pursued children through parental gatekeepers. Although she does not believe that any child took part in this study against his or her will (and she refused some interviews proffered by parents on presumed consent), the study clearly did not provide enough incentive to children in this age group to participate without additional input from parents. This raises questions about autonomy, motive, inducement, and representativeness in research with children, and the balances between them, which researchers need to address. Of the reasons researchers attribute to participants' engagement in qualitative research (Clark 2010) perhaps economic interest was the most resonant with children considering taking part in this particular study. Given that, the financial inducement (the chance to win a prize draw) may have been too remote. Participation in research is also likely to be linked to a person's sense of their contribution being valuable and valued. Children's lesser sense of authority in the research process is suggested in the following sections.

\section{Multiple (but uneven) perspectives}

Research from multiple perspectives can capture in detail the processes by which macro-level social constructions of family life (and of gender and generation within it) are played out, re-enforced and negotiated in families. Ribbens McCarthy, Holland, and Gillies (2003) note that multiple perspectives arise: between different standpoints - for example, mothers, fathers, teenagers; between different members within a family (mother X, father X, daughter X, and son X); between different families (possibly characterized by standpoints of say class or ethnicity); and within individual accounts. A multiple perspectives approach in this study allowed the analysis of data within and across families. From a standpoint perspective it allowed us to compare and contrast the views and experiences of mothers, fathers, sons, and daughters, and also those of lone-parent households versus couple households ${ }^{4}$. But the fact that respondents were in family groups had additional advantages. We could use all of the datasets for one family together to see a picture of how the household operated as a unit, while at the same time maintaining the integrity and visibility of individual experiences. Family-level analysis was invaluable for understanding the processes at play in doing family, gender, and generation, and the complex temporal interconnections between

\footnotetext{
${ }^{3}$ In a previous study with children in the same age category recruited solely through schools, using a variety of recruitment pathways, the highest rates occurred where information composed by the researchers was sent out by the school on its own notepaper to parents at their home addresses (Lewis et al., 2008).

${ }^{4}$ The sample was too small to allow any meaningful analysis of class or ethnicity.
} 
family members and the "outside world". It allowed us to focus on the subjective and relational construction of family positions: What are the processes that lead to the instantiation of mothering, fathering, and being a (teenage) son or daughter; and how do individuals negotiate their own and other family members' position in the gendered and generational family order? Finally, researching from multiple perspectives also allowed us to explicate both agency and constraint for all family members, regardless of their positioning in the familial or social hierarchy.

Within a context of generational power relations operating beyond and within the research encounter, one of the challenges in research from multiple perspectives is in positioning the child's perspective alongside all other participants as an equal player in the research. In what follows we reflect on how this played out in this study on family life. Firstly, to set the scene, we point out that the presentation, focus, location, and methods of the research may have enhanced the "family as joint project" perspective and led participants to focus on the familial. In the individual interviews family members sometimes: expressed worries about being overheard; remained acutely aware that the researcher is a possible source of information on other family members' accounts; and that the researcher will be considering what each interviewee says alongside the accounts of other family members.

Whilst a consideration of the influence of methods on the data produced is relevant to all research, here we reflect on whether these considerations may articulate differently with parents and with children. Certainly we heard less about resistance to parental authority in children's accounts than in a previous project involving interviews with children of the same age band only (and not their parents) in a school setting (Lewis et al., 2008). In the current study, on more than one occasion an adult interviewee asked the interviewer what a child or a partner had said in response to a question (this information was not disclosed), while children made no such enquiries, perhaps indicating their lesser sense of authority within the interview process. We have argued above that researching family processes entangles the researcher in family dynamics and hierarchies, and that these experiences should not be bracketed off as ethical issues, because they are also important data. With reference to this, adults' requests for information on their children or partners illustrate how the interview process becomes an arena for the enactment of generational hierarchies and notions of coupledom (the double hermeneutic). Lastly, while the research did not assume a "hierarchy of credibility" (Becker, 1967, p. 241) based on generation, we cannot be sure whether children perceived this, nor predict how this may have affected their accounts. Conversely, parents may have assumed that the researcher would "side" with them. The following example from an HHP suggests that this may have been the case, although the interviewer was also able to use the joint interview to elicit the views of the child which may otherwise have been drowned out:

I: [Reading from sheet] Monitoring school progress and homework

SON: Me with Mum's input.

MUM: Do you think? I don't.

I: [To son] So do you think - you think that's not right? [To mum] So Lewis thinks him with a bit of you.

MUM: [To son] How often do you say "I'm going to do my homework"? Never. How often do I say "Get that homework done!"? Quite often.

SON: So it's me and you shared. 
MUM: No! It's me!

SON: That's not fair!

MUM: Yes it is fair!

SON: No it's not. Because I'm the one actually doing it.

MUM: If Sophie had been here the day before yesterday. [...] Because you only do it when I'm breathing hard down your neck.

SON: Alright, alright.

DAD: How about [mum] with Lewis' input?

SON: Yes.

MUM: Yeah go on then.

DAD: I think that's looking a bit favourably on the situation, but...

MUM: But it's on there [pointing to the tape recorder]. The conversation's on there.

Researching family life from multiple perspectives gives invaluable insight into social processes of doing family, generation, and gender, and how these processes are perceived. But extra effort is required to both capture and hear the voices of children. This reflects their position in the familial and social hierarchy and also the fact that commonly parents (mothers) are seen as having ultimate responsibility and accountability for family life and are therefore granted a high degree of authority in representing it.

\section{The utility of particular research tools in hearing children's voices}

As noted at the start of this paper, the study was based on an understanding of temporality as multifaceted (including duration, pace, juncture), and as possessing political, moral, symbolic, and experiential dimensions. The use of multiple qualitative methods served to "widen the net and tighten the mesh" to better capture this range and complexity. On the one hand the different research tools were designed to capture different aspects of temporality. But there was also a degree of overlap between the data produced in each of them, which increased the chance of capturing data on any one issue. Multiple methods allowed for the integration of data from different sources on single topics, or on different dimensions of the phenomenon. This produced accounts which reflected multi-vocality and multi-facetedness and commonalities (see Moran-Ellis et al., 2006 on integrating data generated via multiple methods). In this section we reflect on the utility of the different research tools in meeting the challenge of hearing children's voices and learning about children's lives.

Diaries as research tools hold a number of advantages. They afford the research participant greater control of the "research agenda", facilitate reflexivity (Elliot, 1997), and can tap into respondents over time and, therefore, in a number of contexts and moods (Alaszewski, 2006). Rather than the more retrospective interview accounts, diaries record "an ever-changing present” (Plummer, 1990, p. 18). In this study the diaries allowed for very rich data. Some were particularly good at capturing writers' awareness of other people's needs and preferences, for example "active sensibility" (Mason, 1996), as well as the moral economy of time-use. They also revealed frustrations and resentments that had not emerged 
in interviews. But only seven participants submitted diaries, and these vary considerably in the amount of detail and reflexivity involved. This is likely to reflect different communication preferences and competencies, but also varying degrees of confidence in expressing one's experiences in this way to an outsider, and feeling that these have value. Although generation was not the only issue here, the two children's diaries in particular tended to be more like a list of events, suggesting that they were not a good way of tapping into children's subjective experience of time. Children's reluctance to open themselves up further to the researcher's gaze (by limiting the detail in diaries, or declining to complete them at all) may also reflect the structural conditions of their lives that position them as surveilled and accountable $-\mathrm{a}$ position which was often at an acute stage of renegotiation for the 14 and 15 year olds in this study, as we have argued above.

The PITO complemented diaries in picking up what Mason (1996) calls the "sentient activity" involved in relational care, and in taking responsibility for the management of (own and other people's) time; for instance, "keeping an eye on the kitchen clock as I get ready to go to work" and "looking at the stuff stuck to the fridge to see whether [X] needs a packed lunch today". The PITOs gave a strong indication of the link between the roles of primary carer and time manager. These dual responsibilities were highly generationed (as well as gendered) since analysis across the datasets indicated that, while children in the study were fairly self-sufficient in managing their own time, they did not engage in managing other people's time. We suggest that this reflected the generationed hierarchy within families. The fact that more PITOs were completed by primary carer/time managers than others (nine of the 14) possibly signifies their greater affinity with and interest in the roles that the PITO revealed. In other words, because of their structured family position, the PITO appeared to lack salience for child participants in the research, and that silence is itself revealing.

The HHP interview technique worked well on a number of levels. This was always done first. Harden et al. (2012) chose to do sole interviews before joint family interviews in the hope that research relationships established in one-to-one interviews would facilitate group discussion, and make children in particular feel more empowered to speak in the group setting. We found that doing the HHP first allowed participants to orientate themselves to the researcher and to the research as a group, rather than in isolation, which seemed to put children at ease quickly. It may also have been reassuring for parents to get to know the researcher in this way before she interviewed their child. The very hands-on, informal nature of the process (with its chart, coloured stickers, and scissors) usually done around a kitchen table, aided in establishing a relaxed atmosphere and led to what appeared to be open discussion and negotiation (which were treated as data). The researcher always invited the child to be the one in charge of the stickers, which gave them a greater degree of control in shaping or closing discussions. The fact that participants created an artefact which they could then reflect on gave all participants greater ownership of the data than straightforward interviews; adult and child respondents quite often took the opportunity presented to them to shape the research tool (by putting two stickers in a row or for creating new columns or rows) or to interrogate the selection of tasks included in the HHP.

\section{Discussion and Conclusions}

As we hope to have shown in this paper, whatever the substantive focus, sociological research with children and on generationing must engage with the challenges that arise out of attempts to operationalise particular epistemologies. There is a constant danger that "research with children" is treated primarily as a question of methods. Here we have tried to draw attention to the sometimes contradictory and paradoxical relationship between methods 
(based on fixed categories) and epistemological theories (such as social constructionism). The contradictions that arise between using fixed categories to investigate dynamic practices and aspects of the social world have to be managed, since categories are part and parcel of the production of high quality research: sampling frames, ethical practice requirements, instrument design, and so on. This demands more than a rationale for selecting an age group, or a particular method in advance of entering the field. As the social interaction on the appropriate bedtime for a 14 year old illustrates, the ways in which a construct intersects with a social constructionist approach to intergenerational relations in the process of doing the research can itself reveal aspects of the phenomenon that might otherwise pass unnoticed. In this respect such interactions can be positioned as data, and analysed to examine the interplay of structure and agency, and the materiality and conditions of intergenerational relations.

Similarly, the efforts needed to recruit children to the study, to provide them with salient methods with which to tell us about their experiences, and to hear their voice amid the throng of parents' voices, tell us much about generational positioning.

Whilst these issues are not confined to childhood research, they are perhaps intensified here, due to the societal positioning of children and of intergenerational relations (structural, material, and discursive). Working dialectically with these contradictions can also provide points of intersection between childhood studies and sociology more generally, where sociological theory can be informed and enriched by the contradictions of empirical research with children. 


\section{References}

Adam, B. (1998). Timescapes of modernity. London: Routledge. http://dx.doi.org/10.4324/9780203981382

Adam, B. (2000). The temporal gaze: The challenge for social theory in the context of GM food. British Journal of Sociology, 51(1), 125-142. http://dx.doi.org/10.1080/000713100358462

Adam, B. (2004). Time. Cambridge, UK: Polity Press.

Alanen, L., \& Mayall, B. (Eds.). (2001). Conceptualizing child-adult relations. London Routledge-Falmer. http://dx.doi.org/10.4324/9780203467220

Alaszewski, A. (2006). Using diaries for social research. London: Sage.

Alderson, P. (1995) Listening to children: Children, ethics and social research. London: Barnardo's

Becker, H. S. (1967). Whose side are we on? Social Problems, 14(3), 239-247. http://dx.doi.org/10.2307/799147

Brannen, J. (1996). Discourses of adolescence: Young people’s independence and autonomy within families. In J. Brannen \& M. O’Brien (Eds.), Children in families: Research and policy (pp.114-129). London: Falmer.

Craig, L. (2007). Contemporary motherhood: The impact of children on adult time. Aldershot, UK: Ashgate

Christensen, P., \& James, A. (2000). Childhood diversity and commonality: Some methodological insights. In P. Christensen \& A. James (Eds.), Research with children: Perspectives and practices (pp. 156-172). London: Falmer Press.

Clark, T. (2010). On 'being researched': Why do people engage with qualitative research? Qualitative Research, 10(4), 399-419. http://dx.doi.org/10.1177/1468794110366796

Daly, K. (1996). Families and time: Keeping pace in a hurried culture. Thousand Oaks, CA: Sage. http://dx.doi.org/10.4135/9781483327792

Davies, K. (1990). Women, time and the weaving of the strands of everyday life. Aldershot, UK: Avebury.

Davis, J. (1998). Understanding the meanings of children: A reflexive process. Children \& Society, 12(5), 325-335. http://dx.doi.org/10.1111/j.1099-0860.1998.tb00089.x

Doucet, A. (1996). Encouraging voices: Towards more creative methods for collecting data on gender and household labour. In L. Morris \& E. Lyon (Eds.), Gender relations in public and private (pp. 156-173). Houndmills, UK: Macmillan. http://dx.doi.org/10.1007/978-1-349-24543-7_9

Doucet, A. (2000). “There's a huge gulf between me as a male carer and women”: Gender, domestic responsibility, and the community as an institutional arena. Community, Work and Family, 3(2), 163-184. http://dx.doi.org/10.1080/713658907

Doucet, A. (2001). "You see the need perhaps more clearly than I have": Exploring gendered processes of domestic responsibility. Journal of Family Issues, 22(3), 328-357. http://dx.doi.org/10.1177/019251301022003004 
International Journal of Child, Youth, and Family Studies (2014): 5(4.1) 666-685

Doucet, A. (2006). Do men mother? Toronto: University of Toronto Press.

Elliott, H. (1997). The use of diaries in sociological research on health experience. Sociological Research Online, 2(2), 1-13. http://dx.doi.org/10.5153/sro.38

Everingham, C. (2002). Engendering time: Gender equity and discourses of workplace flexibility. Time \& Society, 11(2), 335-351.

Gabb, J. (2008). Researching intimacy in families. Houndmills, Basingstoke, UK: Palgrave Macmillan.

Galinsky, E. (1999). Ask the children: What America's children really think about working parents. New York: William Morrow.

Gershuny, J. (2004). Time, through the life course, in the family. In J. Scott, J. Treas, \& M. Richards (Eds.), The Blackwell companion to the sociology of families (pp. 158-177). Oxford: Blackwell. http://dx.doi.org/10.1002/9780470999004.ch10

Giddens, A. (1993). New rules of sociological method: A positive critique of interpretative sociologies (2nd ed.). Stanford, CA: Stanford University Press

Gillies, V., Holland, J., \& Ribbens McCarthy, J. (2003). Past / present / future: Time and the meaning of change in the 'family'. In G. Allan \& G. Jones (Eds.), Social relations and the life course (pp. 31-48). Basingstoke, UK: Palgrave Macmillan.

Gillies, V., Ribbens McCarthy, J., \& Holland, J. (2001). Pulling together, pulling apart. London: Family Policy Studies Centre for the Joseph Rowntree Foundation.

Harden, J., MacLean, A., Backett-Milburn, K., \& Cunningham-Burley, S. (2012). The 'family-work project': Children's and parents' experiences of working parenthood. Families, Societies and Relationships, 1(2), 207-222. http://dx.doi.org/10.1332/204674312x645529

Harden, J., Scott, S., Backett-Milburn, K., \& Jackson, S. (2000). Can't talk, won't talk? Methodological issues in researching children, Sociological Research Online 5(2). http://www.socresonline.org.uk/5/2/harden.html

Henwood, K., Griffin, C., \& Phoenix, A. (1998). Introduction. In K. Henwood, C. Griffin, \& A. Phoenix (Eds.), Standpoints and differences: Essays in the practice of feminist psychology. London: Sage.

Hutchby, I., \& Moran-Ellis, J. (Eds.). (1998). Children and social competence: Arenas of action. London: Falmer Press.

James, A., Jenks, C., \& Prout, A. (1998). Theorizing childhood. Cambridge: Polity Press.

James, A., \& Prout, A. (1990). Constructing and reconstructing childhood. Basingstoke, UK: Falmer Press.

Jurczyk, K. (1998). Time in women's everyday lives: Between self-determination and conflicting demands. Time \& Society, 7(2), 283-308. http://dx.doi.org/10.1177/0961463x98007002007 
Kellett, M., Forrest, R., Dent, N., \& Ward, S. (2004) 'Just teach us the skills please, we'll do the rest': Empowering ten-year olds as active researchers. Children \& Society, 18(5), 329-343. http://dx.doi.org/10.1002/chi.807

Lewis, J., Sarre, S., \& Burton, J. (2007). Dependence and independence: Perceptions and management of risk in respect of children aged 12-16 in families with working parents. Community, Work and Family, 10(1), 75-92. http://dx.doi.org/10.1080/13668800601110827

Lewis, J., Noden, P., \& Sarre, S. (2008). Parents’ working hours: Adolescent children’s views and experiences. Children \& Society, 22(6), 429-439. http://dx.doi.org/10.1111/j.1099-0860.2007.00124.x

Mason, J. (1996). Gender, care and sensibility in family and kin relationships. In J. Holland \& L. Adkins (Eds.), Sex, sensibility and the gendered body (pp. 15-36). Houndsmills, UK: Macmillan Press. http://dx.doi.org/10.1007/978-1-349-24536-9_2

Moran-Ellis J., Alexander, V., Cronin, A., Dickinson, M., Fielding, J., Sleney, J., \& Thomas, H. (2006). Triangulation and integration: Processes, claims and implications. Qualitative Research, 6(1), 45-59. http://dx.doi.org/10.1177/1468794106058870

Morgan, D. (1996). Family connections. Cambridge: Polity Press.

Morgan, D. (2011). Rethinking family practices. Houndmills, UK: Palgrave Macmillan.

Office for National Statistics [ONS]. (2008). Focus on gender: Work and family. Retrieved January 26, 2014, from http://www.ons.gov.uk/ons/publications/re-reference-tables.html?edition=tcm\%3A77$\underline{51144}$

Plummer, K. (1990). Documents of life: An introduction to the problems and literature of a humanistic method (2nd ed.). London: Unwin Hyman.

Qvortrup, J. (1994). Childhood matters: An introduction. In J. Qvortrup, M. Bardy, G. Sgritta, \& H. Wintersberger (Eds.), Childhood matters: Social theory, practice and politics (pp. 1-23) Aldershot, UK: Avebury.

Ribbens McCarthy, J., Holland, J., \& Gillies, V. (2003). Multiple perspectives on the 'family' lives of young people: Methodological and theoretical issues in case study research. International Journal of Social Research Methodology, 6(1), 1-23. http://dx.doi.org/10.1080/13645570305052

Sarre, S. (2010). Parental regulation of teenagers’ time: Processes and meanings. Childhood, 17(1), 61-75. http://dx.doi.org/10.1177/0907568209351551

Sarre, S. (2011). Temporality in families with teenagers and its articulation with gender and generation. Doctoral dissertation, Department of Sociology, University of Surrey.

Sarre, S. (2013). Time in reconstructing the (school) child. Childhood, 20(4), 521-534. http://dx.doi.org/10.1177/0907568212475100

Solberg, A. (1996). The challenge in child research: From 'being' to 'doing'. In J. Brannen \& M. O’Brien (Eds.), Children in families (pp. 53-65). London: Falmer Press.

Southerton, D. (2003). 'Squeezing time': Allocating practices, coordinating networks and scheduling society. Time \& Society, 12(1), 5-25. http://dx.doi.org/10.1177/0961463×03012001001 
International Journal of Child, Youth, and Family Studies (2014): 5(4.1) 666-685

Southerton, D., \& Tomlinson, M. (2005). 'Pressed for time' - the differential impacts of a 'time squeeze'. The Sociological Review, 53(2), 215-239. http://dx.doi.org/10.1111/j.1467-954x.2005.00511.x

Sullivan, O. (1997). Time waits for no (wo)man: An investigation of the gendered experience of domestic time. Sociology, 31(2), 221-239. http://dx.doi.org/10.1177/0038038597031002003

Zeiher, H. (2001). Dependent, independent and interdependent relations: Children as members of the family household in West Berlin. In L. Alanen \& B. Mayall (Eds.), Conceptualizing child-adult relations (pp. 37-53). London: Routledge. 